\title{
AGEING AND WEAKENING SOCIAL COHESION AMONG STROKE PATIENTS IN MANADO
}

\author{
Sekplin A. S. Sekeon ${ }^{1)}$, Arthur H. P. Mawuntu²), \\ Mieke A. H. N. Kembuan²) \\ 1)Faculty of Public Health, Sam Ratulangi University, Manado \\ 2)Department of Neurology, Faculty of Medicine, \\ Sam Ratulangi University, Manado
}

\begin{abstract}
Background: Stroke is one of the major public health problem worldwide. Data from several hospital in Indonesia showed that stroke is the leading cause of mortality among adults in Indonesia. Stroke patients experience diminishing quality of life. This study aimed to determine the effect of ageing on weakening social cohesion among stroke patients in Manado.

Subjects and Method: This was an analytic observational study with cross sectional design. This study was conducted in Manado, North Sulawesi. A sample of 42 ischemic stroke patients were selected for this study from several hospitals in Manado by stratified random sampling. The dependent variable was social cohesion. The independent variable was age. The sample patients were divided into 2 age groups: <60 years old (non-geriatric patients) and $\geq$ 60 years old (geriatric patients). The data were collected by questionnaire. Data on stroke diagnosis was obtained from the medical record. The data were analyzed using Odd Ratio and Chi Square.

Results: Mean (SD) age of stroke patients was 57.6 years (12.0 years). Proportion of geriatric stroke patients (aged $\geq 60$ years old) was $38.1 \%$. Female patients were $57.1 \%$. Patients with $\geq$ high school attainment or higher were 42.9\%. Patients belonging to Minahasa ethnic was $76.2 \%$. The proportion of poor social cohesion was $37.5 \%$ among geriatric patients and 11.5\% among non-geriatric patients. Ageing was associated with poorer social cohesion $(\mathrm{OR}=4.60 ; 95 \% \mathrm{CI}=0.95$ to $22.16 ; \mathrm{p}=0.046)$.

Conclusion: Ageing is associated with poorer social cohesion among ischemic stroke patients.
\end{abstract}

Keywords: ageing, social cohesion, stroke patients

Correspondence: Sekplin AS Sekeon. Faculty of Public Health, Sam Ratulangi University, Manado, North Sulawesi. Email: sekplin@yahoo.com. Mobile: +6281244058656 